\title{
EFFECTIVE Coverage Of LEARNINg DOMAINS IN STUDENTS ASSESSMENT BY LECTURERS OF CROSS River UNiversity OF TECHNOLOgY CALABAR NigERIA
}

\author{
Ntu n. Nkomo, Henry ojating \\ Cross River University of Technology \\ Calabar, Nigeria
}

\begin{abstract}
The study investigated the degree of coverage of the three domains of learning during assessment of students by lecturers in Cross River University of Technology Calabar, Nigeria. The three learning domains in education are the cognitive, affective and psychomotor domains. Cognitive learning domain behavior involves thinking, reasoning, memorizing, comprehension, calculation, analyzing. Affective learning involves feeling, valuing, interest, responding. While psychomotor includes physical activities such as coordination and use of motor skills measured in speed, precision, distance and procedures. Two hypotheses were formulated to test the expected level coverage of learning domains by lecturers in Cross River University of Technology. The study population comprised all academic staff in Cross River University of Technology, and 100 lecturers were randomly selected as sample for this study. Data collection instrument was a facts finding questionnaire titled learning domain coverage questionnaire. The major findings were that learning domains coverage in continuous assessment tests by academics in Cross River University of Technology was not significantly higher than the expected. There was also no significant difference in learning domain coverage among faculties in Cross River University of Technology. It was recommended that continuous assessment tests should ensure adequate coverage of the learning domain particularly the cognitive and psychomotor domains. Seminars and workshops should be organized for all academic staff by test experts.
\end{abstract}

\section{KEYWORDS:}

Affective domain, cognitive domain, continuous assessment, learning objectives, psychomotor domains.

\section{INTRODUCTION}

The rationale for the policy on continuous assessment in the education system was basically to create opportunities for the learner to be assessed many times before the term ends. Joshua (2012) points out "the child/learner is assessed not only in the academic area a knowledge acquired over the period but also in terms of behaviour task performance, attitude and other affective and psychomotor characteristics". The idea of continuous assessment was borne by the fact that one examination was not a reliable parameter for assessing learning outcomes, since during the examination, the examine could fall sick, be faced with pressing psychological and social problems, or may otherwise cheat in any way to earn grades during the examination period. In continuous assessment the learner is cumulatively assessed during the course of the programme

DOI : $10.5121 /$ ije.2018.6403 
and guiding feed backs are provided to both the teacher and learner for adjustment where necessary.

The three domains of learning behaviour required to be assessed are cognitive domain, affective domain and psychomotor domain. Summarily according to Rather (2006) cognitive learning behaviour involves changes brought about in performing activities like thinking, reasoning, memorizing, comprehending, calculating, analysis etc, affective learning behaviour involves changes brought about by feeling, valuing, interest and attitude while psychomotor involves physical activities, coordination and use of motor skills measured in terms of precision, speed, distance, procedures and technique.

It is however being observed that more emphasis is placed in the cognitive domain in the assessment practices. In other words, learning and measurement in the effective and psychomotor domains are largely ignored or de-emphasized. This inadequacy in the expectation of equitable coverage of learning domain during teaching and measurement may have occurred due to lack of required skills in assessing learning outcomes in those domains. Further explanation on expected coverage of learning domain in assessment given by West African Examination Council (WAEC:2007) affirms that assessment of students learning behaviour is expected be carried out in totality that is assessing the students in all activities involving cognitive, affective and psychomotor behaviour. The emphasis on cognitive domain in assessments by teachers at the neglect of other was further stated by Anikweze (2012) "The flaws identified with the implementation of Continuous Assessment (CA) in Nigeria is that teachers over-emphasize the cognitive domain to the neglect of affective and psychomotor domains, thereby diminishing the comprehensive quality in continuous assessment". Research findings by Adetayo (2008) suggest in the same vein that teachers do not give credence to the assessment of affective and psychomotor domains of educational objectives presumably because of ignorance about the assessment instruments. In a similar study to analyze the coverage of learning domains in continuous assessment tests, Nwachukwu and Ogudo (2014) in Delta State Nigeria studied 1080 teachers from secondary schools and found that teachers concentrate significantly in the assessment of cognitive domain of behaviour objectives. Findings by Ennosho and Badra (2000) Akinsola and James (2004) quoted in Nwachukwu and Ogudo (2014) found that teachers are more comfortable with the assessment of cognitive learning behaviour.

The present study therefore seeks to determine the trend of learning domain coverage in continuous assessment by lecturers in Cross River University of Technology (CRUTECH) Nigeria being that CRUTECH is basically a University of Technology where learning behaviour require physical skills or psychomotor activities as well as other domains.

\section{Purpose Of The Study}

The main purpose of this study is to find out the extent to which learning domain coverage in continuous assessment is achieved by academics of Cross River University of Technology, Nigeria. The study therefore had the following specific objectives.

i. To determine the extent to which the three domains of learning are assessed by academics in continuous assessments.

ii. To find out the difference in learning domain coverage among faculties of the Cross River University of Technology. 


\section{Research Hypotheses}

The following hypotheses were tested.

i. Learning domain coverage in continuous assessment by academics in Cross River University of Technology is not significantly higher than expected.

ii. There is no significant difference in learning domains coverage among faculties of the Cross River University of Technology Nigeria.

\section{METHODOLOGY}

The research design adopted for this study was the descriptive survey; this is because the study basically described the trend of assessment as it is carried out by lecturers. The expost-facto method was also adopted because the research studied the phenomena after they had occurred. Also that the variables were not inherently manipulated by the researchers. The study population comprised all academic staff in six faculties of Cross River University of Technology Calabar, Nigeria approximately 300 academic staff in the following faculties, engineering, sciences, education, management sciences, environmental sciences and communication technology were the study population.

The sampling technique adopted to select the sample was the stratified simple random sampling technique in other to ascertain a proportional representation of respondents form all the faculties. A total of 100 academics from all the faculties formed the sample of the present study.

\section{INSTRUMENTATION}

The data collection instrument was a facts finding questionnaire designed by the authors titled Learning Domain Coverage Questionnaire (LDCQ) was trial tested against 18 academic staff in a population outside the target population of this study. The reliability coefficient of 0.92 was found using Cranach Alpha, indicating that the instrument was reliable.

\section{DATA ANALYSIS}

Data for the two hypotheses were analyzed using the population t-test to determine the learning domain coverage in continuous assessment and one way analysis of variance (ANOVA) to determine the significance of difference in learning domain coverage among Faculties of the Cross River University of Technology Nigeria.

HO: Learning domain coverage in continuous assessment by CRUTECH

\section{Data Analysis}

HO 1 Learning domain coverage in continuous assessment by CRUTECH academic is not significantly higher than the expected

HO2: $\quad$ There is no significant difference in learning domain coverage among faculties of the Cross River University of Technology 


\section{Hypothesis One}

This hypothesis, in its null form, stated that learning domain coverage in continuous assessment by CRUTECH academic is not significantly higher than expected.

The population t-test was applied in testing this hypothesis at .05 significance level. The expected or population mean $(\mu)$ for cognitive, affective and psychomotor learning domain coverage were $15,12.5$ and 17.5 respectively. These were obtained by the formular.

$$
\mu=\underline{n}(a+b)
$$

Where:

$\mu=$ expected mean

$\mathrm{n}=$ No. Of items under each domain

$\mathrm{a}=$ minimum score per item

$\mathrm{b}=$ maximum score per item

The results of the analysis are presented in table 1

TABLE 1

Population t-test analysis of Learning Domain Coverage in Continuous

Assessment $(\mathrm{N}=100)$

\begin{tabular}{lcllll}
\hline Learning domain & Mean & Std Dev. & $\begin{array}{l}\text { Population } \\
\text { mean }(\mu)\end{array}$ & t-value & p-value \\
& & & 15.0 & $24.149 *$ & .000 \\
\hline Cognitive domain & 20.78 & 2.39 & 12.5 & $13.278^{*}$ & .000 \\
Affective domain & 16.11 & 2.72 & 17.5 & $11.090^{*}$ & .000 \\
Psychomotor domain 21.81 & 3.89 & & & \\
\hline
\end{tabular}

From table 1, the p-value (.000) for each of the learning domains is less than the chosen level of significance (.05). Based on this outcome, the null hypothesis is rejected. This means that Learning Domain Coverage in Continuous Assessment by CRUTECH academics is significantly higher than expected.

\section{Hypothesis two}

The null form of this hypothesis stated that there is no significant difference in Learning Domain Coverage Among Faculties of the Cross River University of Technology

The one-way analysis of variance (ANOVA) was applied in testing this hypothesis at .05 level of significance with Faculties of CRUTECH as factor and learning domain coverage as dependent variable. The result of the analysis are summarized and presented in table 2. 
International Journal of Education (IJE) Vol.6, No.4, December 2018

TABLE 2

Analysis of variance of learning domain coverage in CRUTECH $(\mathrm{N}=100)$

\begin{tabular}{|c|c|c|c|c|c|c|}
\hline $\begin{array}{l}\text { Learning } \\
\text { Domain }\end{array}$ & Faculty & $\mathbf{N}$ & Mean $x$ & $\begin{array}{l}\text { std } \\
\text { Deviation }\end{array}$ & \multicolumn{2}{|c|}{$\begin{array}{l}\text { std } \\
\text { Error }\end{array}$} \\
\hline Cognitive & Engineering & 20 & 20.65 & 2.62 & \multicolumn{2}{|c|}{0.58613} \\
\hline Domain & Sciences & 33 & 21.12 & 2.52 & \multicolumn{2}{|c|}{0.43900} \\
\hline & Education & 33 & 20.64 & 2.12 & \multicolumn{2}{|c|}{0.36881} \\
\hline & Mgt. Sciences & 3 & 19.00 & 2.65 & \multicolumn{2}{|c|}{1.52753} \\
\hline & Environ. Sciences & 5 & 21.80 & 1.79 & \multicolumn{2}{|c|}{0.8000} \\
\hline & Comm. Technology & 6 & 20.17 & 2.86 & \multicolumn{2}{|c|}{1.16667} \\
\hline & Total & 100 & 20.78 & 2.39 & \multicolumn{2}{|c|}{0.23935} \\
\hline Affective & Engineering & 20 & 14.90 & 3.06 & \multicolumn{2}{|c|}{0.68403} \\
\hline Domain & Sciences & 33 & 16.61 & 2.30 & \multicolumn{2}{|c|}{0.40109} \\
\hline & Education & 33 & 16.42 & 2.46 & \multicolumn{2}{|c|}{0.42868} \\
\hline & Mgt. Sciences & 3 & 16.67 & 0.58 & \multicolumn{2}{|c|}{0.33333} \\
\hline & Environ. Sciences & 5 & 16.00 & 4.64 & \multicolumn{2}{|c|}{2.07364} \\
\hline & Comm. Technology & 6 & 15.50 & 3.45 & \multicolumn{2}{|c|}{1.40831} \\
\hline & Total & 100 & 16.11 & 2.72 & \multicolumn{2}{|c|}{0.27188} \\
\hline Psychomotor & Engineering & 20 & 19.80 & 4.57 & \multicolumn{2}{|c|}{1.0238} \\
\hline Domain & Sciences & 33 & 22.79 & 3.45 & \multicolumn{2}{|c|}{0.60107} \\
\hline & Education & 33 & 21.88 & 3.67 & \multicolumn{2}{|c|}{0.63924} \\
\hline & Mgt. Sciences & 3 & 22.33 & 1.53 & \multicolumn{2}{|c|}{0.88192} \\
\hline & Environ. Sciences & 5 & 24.00 & 4.69 & \multicolumn{2}{|c|}{2.09762} \\
\hline \multirow{2}{*}{\multicolumn{2}{|c|}{$\begin{array}{l}\text { Comm. Technology } \\
\text { Total }\end{array}$}} & 6 & 20.66 & 3.08 & \multirow{2}{*}{\multicolumn{2}{|c|}{$\begin{array}{l}1.25610 \\
0.38865 \\
\end{array}$}} \\
\hline & & 100 & 21.81 & 3.89 & & \\
\hline $\begin{array}{l}\text { Learning } \\
\text { domain }\end{array}$ & $\begin{array}{l}\text { Source of } \\
\text { variation }\end{array}$ & $\begin{array}{c}\text { Sum } \\
\text { squares }\end{array}$ & Df & $\begin{array}{l}\text { Mean } \\
\text { Square }\end{array}$ & f-value & p-value \\
\hline \multirow{3}{*}{$\begin{array}{l}\text { Cognitive } \\
\text { Domain }\end{array}$} & Faculty & 21.825 & 5 & 4.365 & \multirow{3}{*}{\multicolumn{2}{|c|}{$0.752 \quad .586$}} \\
\hline & Error & 545.335 & 94 & 5.801 & & \\
\hline & Total & 567.160 & 99 & & & \\
\hline \multirow{3}{*}{$\begin{array}{l}\text { Affective } \\
\text { Domain }\end{array}$} & Faculty & 43.884 & 5 & 8.777 & \multirow{3}{*}{\multicolumn{2}{|c|}{$1.199 \quad .316$}} \\
\hline & Error & 687.906 & 94 & 7.318 & & \\
\hline & Total & 731.790 & 99 & & & \\
\hline \multirow{3}{*}{$\begin{array}{l}\text { Psychomotor } \\
\text { domain }\end{array}$} & Faculty & 145.160 & 5 & 29.032 & \multirow{3}{*}{\multicolumn{2}{|c|}{2.01}} \\
\hline & Error & 1350.23 & 94 & 14.364 & & \\
\hline & Total & 1495.39 & 99 & & & \\
\hline
\end{tabular}

From table 2, the mean (x) scores for eth coverage of the affective domain were the least for all the faculties. Each of the scored less than $20(x<20)$. In the assessment of learning objectives in 
International Journal of Education (IJE) Vol.6, No.4, December 2018

the psychomotor domain, environmental sciences equally task the lead with a mean score of 21.80 in cognitive assessment. They were closely followed by the sciences $(x=21.12)$.

Also, as shown in table 2, the p-value $(.586, .316$ and .083$)$ associated with the computed f-values $(0.752,1.199$ and 2.021) respectively, are each less than the chosen level of significance for the study (.05). Based on these results, the null hypothesis was retained. This means that there is no significant difference in learning domain coverage among faculties of the Cross River University of Technology.

\section{DISCUSSION}

The first finding reveals that learning domain coverage in continuous assessment by academic in Cross River University of Technology is significantly higher than expected. This means that there is a reasonable coverage of the three domains of learning in continuous assessments by academic in CRUTECH.

However the population means of 15.0 for cognitive domain and 17.5 for psychomotor are far higher than 12.5 for affective domain. This finding contradicts Anikweze (2012) and Nwachuwu and Ogudo (2014) who found that secondary school teachers placed more emphasis on the assessment of cognitive behavior at the neglect of psychomotor and affective behaviors. The findings can further be explained that the assessment of the three domains particularly the cognitive and psychomotor are total meeting the expectations stated by WAEC (2001) on coverage of learning domains assessment.

The second finding that there is no significant difference in learning domain coverage among faculties of the Cross River University of Technology indicates that academics in all faculties covered the three domains of learning in their assessments appropriately, this result appears to contradict popular opinions and researchers in the secondary school may be for the reasons that CRUTECH is a University of Technology, where most learning activities revolve around cognitive and psychomotor behaviours. The significant coverage of the learning domains by lecturers of CRUTECH in the second finding could be attributed to the experience and skills of assessments acquired in seminars, workshops and conferences on assessments of the learning domains.

\section{CONCLUSION}

Adequate coverage of the three domains in continuous assessment still posses a major challenge in the measurement of learning outcomes by teacher thus, the emphasis or cognitive learning behaviours at the neglect of others by teachers in their continuous assessment test needs to be urgently addressed, through seminars, workshop and or conferences. In Cross River University of Technology Nigeria. This challenge has become somewhat insignificant.

\section{Recommendation}

i. Proper mentoring of newly employed academic staff by experienced ones should be encouraged.

ii. Knowledge update for academic staff on measurement should be provided through department and faculty seminars and workshops.

iii. Academic staff should be encouraged to attend conferences bordering on assessments. 


\section{REFERENCES}

[1] Adetayo, J. O. (2008), An investigation of assessment practice by teachers business education subject empirical research Vol. 6(3), 25-32.

[2] Anikweze, C. M. (2012), Assessment practices and professional teacher development in the $21^{\text {st }}$ Century, Journal of Global Voice of Educators Vol. 1 (1), 1-6.

[3] Esuhun, I, (2013), Domain of educational objectives social studies teachers questions emphasize in senior higher schools in Ghana. Journal of Education and Practice 4(4), 187-193.

[4] Joshua, M. T. (2012), Fundamentals of tests and measurement in education Calabar: The University of Calabar Press.

[5] Nwachukwu, P. O., \&Ogudo, (2014). The standard of teachers' assessment practice in three domains of learning in Nigerian secondary schools.Journal of Developing Country Students. Vol. 4 (14), 179-182.

[6] Rather, A. R. (2006, Psychology of Earning and Development. New Delhi, India: Discovery Publishing House.

[7] West African Examination Council (2007), Chief examiners Report: WAEC: Author 